\title{
The Review of Saline Water in Desert Management
}

\author{
Maryam Naeimi and GholamReza Zehtabian
}

\begin{abstract}
Considering the population growth rate in the world currently has about 2 percent which is estimated every 35 years to the present, in terms of water needed was double increased. Thus, appropriate management is necessary in order to exploit and optimize the usage of saline water resources. The purpose of this paper is to review recent research on saline water, causes and different usage of saline water. Holes in deserts are locating in the interior part of catchments. They are a gathering closed place for surface water and groundwater elevations, which due to intense evaporation the amount of grown minerals and salt are increased. Depending on the location of the study area the usage of saline water will be different. The findings of this paper suggest that in general direct usage of saline water for agriculture, strengthening rang, forest and fish culture has already created, and while another way which is sweetening the saline water could be applied by consideration of benefits and costs of it.
\end{abstract}

Index Terms-Desert, salinity, management, water.

\section{SALine WATER}

Saline water is a general term for water that contains a significant concentration of dissolved salts. The concentration is usually expressed in parts per million (ppm) of salt. The salinity concentration level (Table 1) used by United States Geological Survey classifies saline water in three categories. Slightly saline water contains around 1,000 to $3,000 \mathrm{ppm}$. Moderately saline water contains roughly 3,000 to $10,000 \mathrm{ppm}$. Highly saline water has around 10,000 to $35,000 \mathrm{ppm}$ of salt. Seawater has a salinity of roughly $35,000 \mathrm{ppm}$, equivalent to $35 \mathrm{~g} / \mathrm{L}$ [7].

TABLE I: WATER SALINITY BASED ON DISSOLVED SALTS IN PARTS PER THOUSAND (\%o) [7]

\begin{tabular}{llll}
\hline \hline Fresh water & Brackish water & Saline water & Brine \\
$<0.5$ & $0.5-30$ & $30-50$ & $>50$ \\
\hline \hline
\end{tabular}

Holes in deserts are locating in the interior part of catchments which are a gathering closed place for surface water and groundwater elevations that due to intense evaporation the amount of grown minerals and salts are increased. Thus, appropriate management is necessary in order to exploit and optimize the usage of saline water resources, vegetation and playa margins hydrophyte and halophyts. They can be acting as food for livestock and the consequence of it would be increasing the production of beef.

Manuscript received October 9, 2011, revised November 4, 2011. This work was supported in part by Department of Reclemation of Arid \&Mountain Provinces, Faculty of Natural Resources, College of Agriculture \& Natural Resources, University of Tehran.

M. Naeimi was Master degree student at University of Tehran, Karaj, Iran (e-mail: ma.naeimi@gmail.com).

Gh. Zehtabian, Full Professor at University of Tehran, Karaj, Iran (e-mail: gh.zehtab@ut.ac.ir).
In addition, marginal lands and soils of the playa with the salty water could be suitable for developing plants such as pistachio and madder [11]. However, new farm and ranch unites could be established. But due to lack of proper drinking water, humans and livestock in these areas couldn't exploit of resources. In other words a lack of fresh water in the desert margins is the most important factor limiting the development of other considering resources.

The objective of this paper is to review the management of water parallel to parameters and possibility of using saline water in semi arid, arid and desert area.

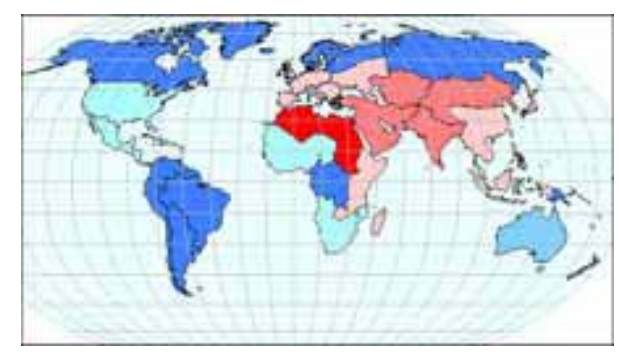

1995

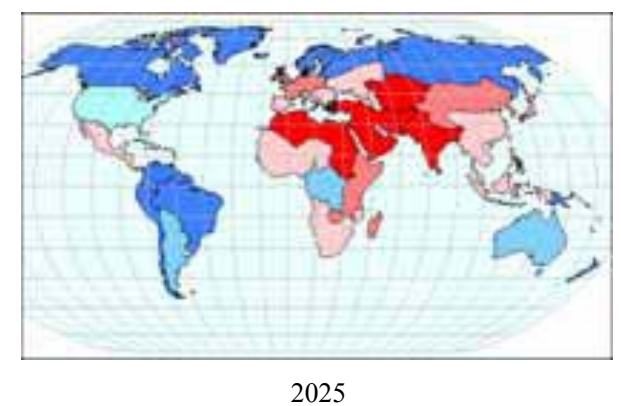

Fig. 1. Global water availability 1995-2025 (Source: UNESCO)

\section{THE WORDS NEEDS INCREASING WATER}

For dry areas it is clear that water, not land, limits agricultural production. Improving water use efficiency and decreasing demand must be major factors in the coping and adaptive strategies for climate change [17]. Supplies of good quality irrigation water are expected to decrease in the future (Fig 1) because the development of new water supplies will not keep pace with the increasing water needs of industries and municipalities [8]. Thus, irrigated agriculture faces the challenge of using less water, in many cases of poorer quality, to provide food and fiber for an expanding population. Some of these future water needs can be met by using more efficiently, but in many cases it will prove necessary to make increased use of municipal wastewaters and irrigation drainage waters. Aside from increased levels of nitrogen, phosphorus, and potassium, the salinity (total salt content) and sodicity (sodium content) of these waters will be higher than the original source of water because of the direct addition of salts to the water and the evapotranspiration that 
occurs as water is used [15]. While the use of these waters may require only minor modifications of existing irrigation and agronomic strategies in most cases, there will be some situations that will require major changes in the crops grown, the method of water application, and the use of soil amendments [8]. On the other hand considering the population growth rate in the world which currently is about two percent, it is estimated that in terms of water needed, every 35 years to the present double increased. According to the following two reasons, firstly in dry lands, water is a limiting factor, and developing of other resources totally depends on it; and secondly generally living standards in arid lands are lower than wet lands. The criticism of management of water in dry lands has showed up when rising standard of living has increased water consumption, in arid lands the need of water is more than wet areas. Taken over much of the river water makes the fall in the water used in coastal rivers. When the quality of this water is largely low, it could not be usable.

\section{Source of SALine WATER}

Main source salinity in arid areas is groundwater, but so long as the static level is low enough capillary action will not be able to bring the salts to the soil surface and groundwater salinity is not necessarily caused soil salinization. Rivers that based semi-arid and arid areas contain large amounts of salt. In highly permeable soils exactly before irrigation, the differences between the amounts of salts in the soil solution may be reached the level of ten times more than irrigation water. Therefore, in low permeable soil the risk of using water that has too much minerals or a moderate amount of sodium ions is greater. Usually the situation getting worse because step by step sodium ions replaced by calcium ions and gradually permeability of soil reduced [7], [10].

\section{Studies Regarding The CAUSe of SAlinity}

\section{A. Natural Causes}

1. Parent material: This material includes native salt dome that 90 to 98 percent of them consists of sodium chloride. Moreover Formation of destruction evaporating-young Marl also affects the salinization. Primary minerals and rocks in the earth's crust which passed the physical and chemical weathering process of environment and entered the soil are the major source of all salt [7].

2. Topography: Slight height difference of two points is enough for forming the difference in salt concentration. The height difference starts from $20 \mathrm{~cm}$. Geomorphologic and hydrological condition can prevent water from escaping and dirt on the floors of stone or an impenetrable underground water table created above, thus salt accumulation was caused by the overcoming of evaporation to penetration.

3. Surface water: Surface water quality is a function of the hydrological conditions of the region.
4. Underground water: The existence of minerals in underground water created greater risk of salinization in soil surface. Critical concentration of chloride and sulphate salts are about 2 to $3 \mathrm{~g} / \mathrm{L}$ and the critical concentration of carbonate minerals is $0.7 \mathrm{~g} / \mathrm{L}$.

5. Climate: Low rainfall, high temperatures, evaporation and extreme hot and dry winds associated with climate factors that caused accumulation of salts.

6. Vegetation: Some plants absorbed underground water and salt from the soil through their roots and emitted by the stem and leave and transported to the surface. These plants during their life, discharge the tiny crystals of salts and after death by decaying of their organs accumulate the salts in soil. Removing native plants from soil, also increase the evaporation rate and salts.

\section{B. Human Factors}

Factors such as irrigation in arid and semiarid regions, large intervals between irrigation, surface irrigation, improper irrigation and drainage methods and poor quality of irrigation in hot and dry seasons increased the trend of salinity. Chemical fertilizers also significantly increased sodium salts, salinity and alkalinity.

Sprinkling of salts on the road surface to break the ice, industrial and domestic sewage pouring into the rivers and waste underground disposal are the most important factors that caused saline water [7],[11].

\section{The Usage OF SAline Water}

The quantity and quality of water as well as the prevailing socio-economic circumstances determine which of these uses is most likely to be appropriate. However, production of crops is one option that could be especially promising for direct use of saline water in water-scarce environments.

\section{A. Direct use of Saline Water}

a. Using of saline water in agriculture

Increasing demands for irrigation water while water resources limited will ultimately lead to reuse and recycle the available water resources. Field drainage, industrial and domestic waste waters are reused and recycled for irrigation in many parts of the world. The water scarcity, has forced farmers to extensively explore the possibility of including saline water in the irrigation regimes of agricultural crops. Strategies of using waters of different salinity levels include: network dilution, in which different quality waters are blended in the supply network; soil dilution, in which altering the use of good and poor quality water takes place according to the availability and crop needs; and switching the use of water qualities during the growing season according to the critical stage of the growth. The choice among these strategies depends on many factors such as water salinity levels, the relative tolerance of the various crops at different stages of growth, soil properties and the cost-benefit analysis of each strategy [6].

There are a number of factors to be considered when using saline water: plant tolerance, irrigation system, water management strategies, irrigation frequency and soil properties [12]. The level of salinity in the water is the prime determinant of its direct use for plant production. 
Higher salinity levels increasingly restrict productivity and the range of plants that can be grown, but a large number of plant species can grow and produce in the presence of salt, particularly animal feed and forage species that can fit well into livestock and mixed farming systems. Russian scientists proved that by artificial soaking of seed, the resistance of plants to salinity of irrigation water increased. In fact the same reaction in them creates as a vaccine in humans creates. Results show that when saline water irrigation started at the appearance of the fourth or the eleventh leaf, a water salinity of $7.5 \mathrm{dS} / \mathrm{m}$ reduced the yield by only about $30 \%$ [14]. Fruits and vegetables are generally sensitive to salinity and their growth and yield drop rapidly with increased levels. Field crops are generally more tolerant, are little affected by low levels of salinity, but their growth and yields diminish quite rapidly as salinity increases. Halophytes, on the other hand, show enhanced growth and yields in the presence of low and moderate salinity that only decline slowly as salinity increases; many are able to grow and reproduce in seawater. The greater resistance of plant, the higher saline water can be used. Also, whatever the efficiency of irrigation is lower, higher salinity of irrigation water can be used. The use of saline irrigation water for high efficiency is not possible and always much more water than the plant requires applied. In this way this method would not saline the land. Type of soil in saline waters is effective. Saline water can be used for lighter texture.

Currently at least twenty per cent of the world's irrigated land is salt affected and/or irrigated with waters containing elevated levels of salts [5]. It should be mentioned that irrigation with saline water without drainage can cause soil salinization. If drainage is not suitable and irrigation water is not too much to wash the soil, use of irrigation water with lower salinity caused the soil salinity relatively after short period of time. Irrigation with saline water was used for carminative planting trees. Although the lifespan of trees decreases with increasing salinity; however, different species of plants have different resistance to salinity. Drip irrigation, provides a greater advantage in using saline water [12]. The system maintains high matric potential and low salt accumulation in the wetting zone, so maintaining a low salinity level in the root zone. In furrow irrigation, salts tend to accumulate in the seed beds [12] because leaching occurs primarily below the furrows. It is essential to observe the following points, when saline water was used:

1. Levelling the land and proper drainage: drainage made the land dry and all the saline water washed out of the ground. In this way plowing and using tractors and other agricultural machines is possible. Proper drainage of saline and salinity control is essential to prevent the lands from higher salinization. Topography in lands prevents the creation of proper drainage network [1].

2. Deep plowing: The results of plowing the ground are increasing the permeability of weather and water and the consequence is better washed out of salts. Usually after the land levelling, deep plowing applied [11].
3. Long irrigation before planting: Before attempting to cultivation, to wash salts from the land fallow or plant, it is necessary to expose the land to irrigation.

4. Select appropriate species: For the use of saline water for irrigation, soil salinity-resistant plants should be selected.

5. Select the appropriate method of cultivation and irrigation, and change them: Proper irrigation prevents salinization in soil. At this time, in desert and dry lands drip irrigation is the best system. The results of Malash et.al (2005) showed that rregardless, the irrigation method, mixed water management practice gave higher growth and yield than alternate irrigation. Moreover growth and yield were high in alternate practice only with fresh water, whereas moderate saline irrigation waters in mixed practice gave the highest values of yield and growth. Thus, the highest yield obtained (3.2 kg/plant) was the result of the combination of drip system and mixed management practice using a ratio of $60 \%$ fresh water with $40 \%$ saline water [12].

6. Select the correct location of seeds in the soil: according to different kind of irrigation system, salt accumulation point in soil was determined and then place the seeds in the soil $[1],[15]$.

8. Light texture soil: Sandy soil is suitable because they have high permeability and hence the washing of minerals is easy to do. Capillary action is limited in this soil [16].

9. Seed planting time: Planting seeds in the fall or early spring is more appropriate [11].

10. Adding organic matter to soil, especially animal fertilizers to prevent direct sun radiation and high evaporation of surface water.

11. Appropriate fertilizer for controlling salinity.

12. Improved water infiltration in the ground.

13. Shortening the period between Irrigation.

14. Prevent evaporation and drying soil.

15. Water reforming and changing the type of irrigation [9].

16. Leaving land without cultivation for too long caused high salt concentration in soil. In the absence of sufficient water for all land, alternative cultivation should be used [9].

17. Washing the soil minerals: Slightly saline water could make the soil saline. However, if there is an excellent drainage, saline water can be used for irrigation. Irrigation causes salts being washed down. Amount of water needed to wash the soil varied depending on the soil type and salinity levels of irrigation water, climate and other factors [1].

Salinity research institute in India proved that establishing salt-tolerant forest and fruit trees plantations, cultivation forages and other high value crop utilizing the saline ground waters might provide for an economic use of abandoned arid [4].

b. Use of saline water for development and strengthening of industrial pastures and medicinal plants [11].

c. Use of saline water for the forest: In saline soils places where the level of underground water is high, Tamarix $s p$. grows well and fast. Wood of this plant is used for particle board. 
d. Use of saline water for leaching and to protect the soil, preventing the advancing desert.

e. Usage of saline water as sea water for irrigation (agriculture with sea water).

f. Use of saline water for energy, food and artificial fertilizers.

g. Use of saline water for fish farming and livestock.

$\mathrm{h}$. Use of salts of saline water and industrial usage: such as mining and thermoelectric-power.

\section{B. Use of Saline Water Desalination (Sweeten)}

Saline water can be desalinated for indirect use in producing high value crops or for other uses, such as drinking water in water-scarce environments.In the absence of fresh water in the region due to the high cost of fresh water the only way is to use salt water and sweeten it. Only two percent of the world's waters are fresh, and the polar ice is also included [2]. Many of migrations caused according to the lack of fresh water in the region. The importance and necessity of fresh water in arid areas and deserts is more specific [13]. Boiling water and change the liquid to vapor was the first way to sweeten the saline water [2]. The cost of sweeten water includes depreciation of primary system, thermal energy consumption, electronic energy for pumps and similar tools, Buildings, public spending and monitoring repair, maintenance, machine work including wages and materials costs.

a. Methods produce fresh water using desalination:

There are several ways in this area. These methods based on distillation, through membranes, freezing, wet building and chemical process. Ways to produce large quantities of water suitable for irrigation is:

1. Distillation and reverse osmosis: sweeten of waters containing enormous quantities of salt like sea water (total dissolved salts 35,000 parts per million or more). This includes heating the saline water and produce steam then it cooled and water was obtained. The first multi-stage system, which was important on large scale, was built in 1960.

2. Reverse osmosis and electro dialyze: sweeten of brackish water (total dissolved salts 3000 to 4000 parts per million). Great progress in this area has been done. An electrolyte chamber with the establishment of an electric current send the positive and negative ions toward different sides and fresh water remains in the middle of membranes. In reverse osmosis the pressure is on saline water. Therefore, the fresh water passes contrary to the natural flow of osmosis semi permeable membrane.

3. Different production can be produced in the process of distillation: In Kuwait, in addition to produce electricity and fresh water, from the leftover water, salt, hydrochloric acid can be produced. Even the magnesium and potassium also obtained. Because of the high cost of sweeten the water, it is not suitable for agriculture and irrigation. However, mixing with some saline water could be offset the costs and can be useful in agriculture.

4. Using solar energy: Amrollahi (1997) investigated this new method called bath condenses. Using solar energy without the use of sophisticated and imported technology and low cost considered in this method. Installing a plastic or glass cover in the humid part of desert then collect and measure the daily fresh water produced from condensation and evaporation from the soil surface. The results show that the average of discharge rate was equivalent to 0.8 liter per day per square meter on the plastic surface was obtained for the local plan. The maximum and minimum discharge was related to July (1.47 liter) and January (0.27 liter) respectively. Factors such as the amount of solar radiation, the depth of water table (static level), structure of soil, salts in soil, and changes in temperature affect the method. In conclusion, extraction of drinking fresh water by this method compared to other available methods was more economic [2].

\section{ECONOMICS ASPECTS OF IRRIGATION WITH SALINE WATER}

a. Expenses:

1 - Drainage (original system and drainage field).

2 - Implementation of irrigation system.

3 - Correction (levelling and washing).

4 - Improvement of industrial (training, services etc).

b. Income

1- The product most common area plants and new plants and increase crop lands.

2 - Development of agriculture related industries.

3 - Improvement of financial power of farmers.

4- Recovery of health and production workers to improve living standards.

\section{REFERENCES}

[1] Alizadeh, A, Relationship between soil, water and plant, Emam Reza University, 2010, chapter 1 (in Persian).

[2] Amrolahi, A, Investigation on the possibility of water extraction from the drainage of desert, University of Tehran, 1997, chapter 5(in Persian).

[3] Beltrán, J. "Irrigation with saline water: benefits and environmental impact”, Agricultural Water Management, vol 40, 2-3, pp. 183-194, 1999 ,

[4] Dagar, J.C, "Opportunities for alternate land uses in salty and water scarcity areas", International Journal of Ecology and Environmental Science, vol 35, 1, pp. 53-66, 2009.

[5] Ghassemi F, Jakeman AJ, Nix HA, "Salinisation of Land and Water Resources: Human Causes, Extent, Management and Case Studies", CABI Publishing: Wallingford, 1995.

[6] Gideon O., Yoel DeMalach, Leonid Gillerman, Itsik D., V.P. Rao, "Improved saline-water use under subsurface drip irrigation", Agricultural Water Management, vol.39, pp 19-33, 1999.

[7] Jaffari, M. Saline soils in natural resources, University of Tehran, 2000, chapter 2 (in Persian).

[8] J.D. Ostera. Review article Irrigation with poor quality water. Agricultural Water Management, vol 25, 3, pp. 271-29, 1994.

[9] Jafari, M. Azarnivand, H. Zehtabian, gh., Jamshidi, A, "Investigation on the quality of water in land degradation in desert area around Damghan”, Biaban, vol 7, 2, pp. 120, 2002 (in Persian).

[10] Kardovani, P. Water resources and its issues in Iran. University of Tehran, 2006, chapter 2 (in Persian).

[11] Kardovani, P. Natural resources conservation soil. 2010, University of Tehran, chapter 3 (in Persian).

[12] Malash a. N, T.J. Flowers, R. Ragab. Effect of irrigation systems and water management practices using saline and non-saline water on tomato production Agricultural Water Management, Biaban, vol.78, pp.25-38, 2005.

[13] Qadir,M., A. Tubeileh, J. Akhtar, A. Larbi, P. S. Minhas, M. A. Khan, "Productivity enhancement of salt-affected environments through crop 
diversification", Land Degradation Development, vol.19, pp. 429-453, 2008.

[14] Pasternak, D., De Malach, Y., and I. Borovic, "Effect of time of application of brackish water on production of processing tomatoes", Agricultural Water Management, vol. 12, 1-2, pp 149-158, 1986.

[15] Sallardini, A. Relationship between soil, water and plant. University of Tehran, 1998, chapter 5 (in Persian).

[16] Zehtabian, gh. Rafie emam, A. Alavi panah, Sk. and Jafari, M, "Investigation on the quality of water in Jajrod River", Biaban, vol. 8, 2, pp. 164, 2003, (in Persian).

[17] R.J. Thomas, "Opportunities to reduce the vulnerability of dry land farmers in Central and West Asia and North africa to climate change", Agriculture, Ecosystems and Environment, Vol 126, pp. 36-45, 2008.

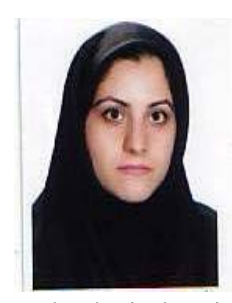

Maryam Naeimi was born in Iran. She studied Range \& Watershed Management (B.Sc.) and Desert Management (M.sc) in Department of Reclamation of Arid \&Mountain Province, Faculty of Natural Resource, College of Agriculture \& Natural Resources, University of Tehran, Karaj, Iran and graduated at 2005 and 2007 respectively. She has studied $\mathrm{PhD}$ in school of Civil and Environmental Engineering in Nanyang Technological University (Singapore). She has more than 4 journal paper and 15 international conferences on her resume. 